\title{
SPECTROPHOTOMETRIC ANALYSIS OF THE KINETIC OF Pd(II) CHLORIDE COMPLEX IONS SORPTION PROCESS FROM DILUTED AQUA SOLUTIONS USING COMMERCIALLY AVAILABLE ACTIVATED CARBON
}

\begin{abstract}
In this paper, results of adsorption kinetic studies of Pd(II) chloride complex ions on activated carbon Organosrob $10 \mathrm{CO}$ are presented. Spectorphotometrical method was applied to investigate the process. Kinetic model was proposed, and fundamental thermodynamic parameters were determined. Proposed kinetic model describes well observed phenomenon in the studied range of concentration of Pd(II) chloride complex ions as well, as concentration of activated carbon.

Keywords: Palladium, recovery, recycling, adsorption, sorption, chloride ions, spectrophotometry
\end{abstract}

\section{Introduction}

Palladium belongs to platinum group metals. It is one of the most often applied metals in catalysis $[1,2]$. Therefore its world consumptions is mainly related to this area. Also, significant amounts of palladium is consumed by jewelry, however live time of those products is significant, and recycling in this area is well developed.

In case of palladium based catalysis, palladium concentration in it, varies in wide range, from several ppm to $100 \%$. Depending on catalyst application, carrier, state, etc., different methods can be applied to recover this metalfrom spend catalysts.

The most often applied method for precious metal recovery is hydrometallurgical method $[3,4]$. This is mainly related to the amounts of recovered metals as well as the amounts of available waste. At the end of every process, there are produced by-products, which may also contain some amounts of precious metals.

To recover palladium from strongly diluted water solutions, its adsorption on activated carbon is proposed [5,6]. It has to be underline, that activated carbon is not expensive reagent. It is resistant to every mineral acid and organic compound. This makes it applicable over a wide range of $\mathrm{pH}$. Thanks to that it can be applied as competitive equivalent for anion exchange resin [7-9]. From the ecological as well as economical point of view, electrochemical method are inappropriate[10,11].

Phenomenon of adsorption of metal ions on activated carbons is well known and was described in many papers [12-18]. However, due to the variety of activated carbon there is no consistent kinetic model with can be applied to describe this process. Therefore, in this paper, kinetic model similar to that proposed in previous paper[19], was used once again to confirm its versatility.

\section{Experimental}

All experiments were carried out in thermostated cyclic glassy reactor. To maintain constant $\mathrm{pH}$, the $0,1 \mathrm{M}$ hydrochloric acid was used. This solution was obtained by a dissolution of concentrated hydrochloric acid (36.5-38\%, A.P., Avantor Performance) in deionized water. Next, the concentration of the obtained solution was controlled by colorimetric titration using sodium hydroxide in the presence of phenolphthalein.

$\operatorname{Pd}(\mathrm{II})$ chloride complex was obtained according to the protocol given in our previous paper [20]. For this purpose, a suitable amount of $\mathrm{PdCl}_{2}$ was dissolved in stoichiometric amount of hydrochloric acid. Thus obtained stock solution was diluted as required to obtain suitable initial concentration of $\operatorname{Pd}(\mathrm{II})$.

The concentration of $\mathrm{Pd}(\mathrm{II})$ in the solution, can be determined from the UV-VIS spectrum using Lambert-Beer low (see eq. (1)). For this purpose spectrophotometer PC2501 was applied (Shimadzu model PC 2501, Japan).

$$
A b s=\varepsilon \cdot l \cdot[P d(I I)]
$$

where:

Abs - absorbance level, A.U.,

$\varepsilon-$ molar absorption coefficient, $\left[\mathrm{dm}^{3} / \mathrm{cm} \cdot \mathrm{mol}\right]$.

$l$ - path length in this case equal to $1,[\mathrm{~cm}]$.

In all experiment, activated carbon Organosorb $10 \mathrm{CO}$ $8 \times 30$ in an unmodified form was applied. This activated carbon is produced by thermal treatment of coconut shells. The size of

\footnotetext{
* AGH UNIVERSITY OF SCIENCE AND TECHNOLOGY, FACULTY OF NON-FERROUS METALS, AL. MICKIEWICZA 30, 30-059 KRAKOW, POLAND

\# Corresponding author: marekw@agh.edu.p
} 

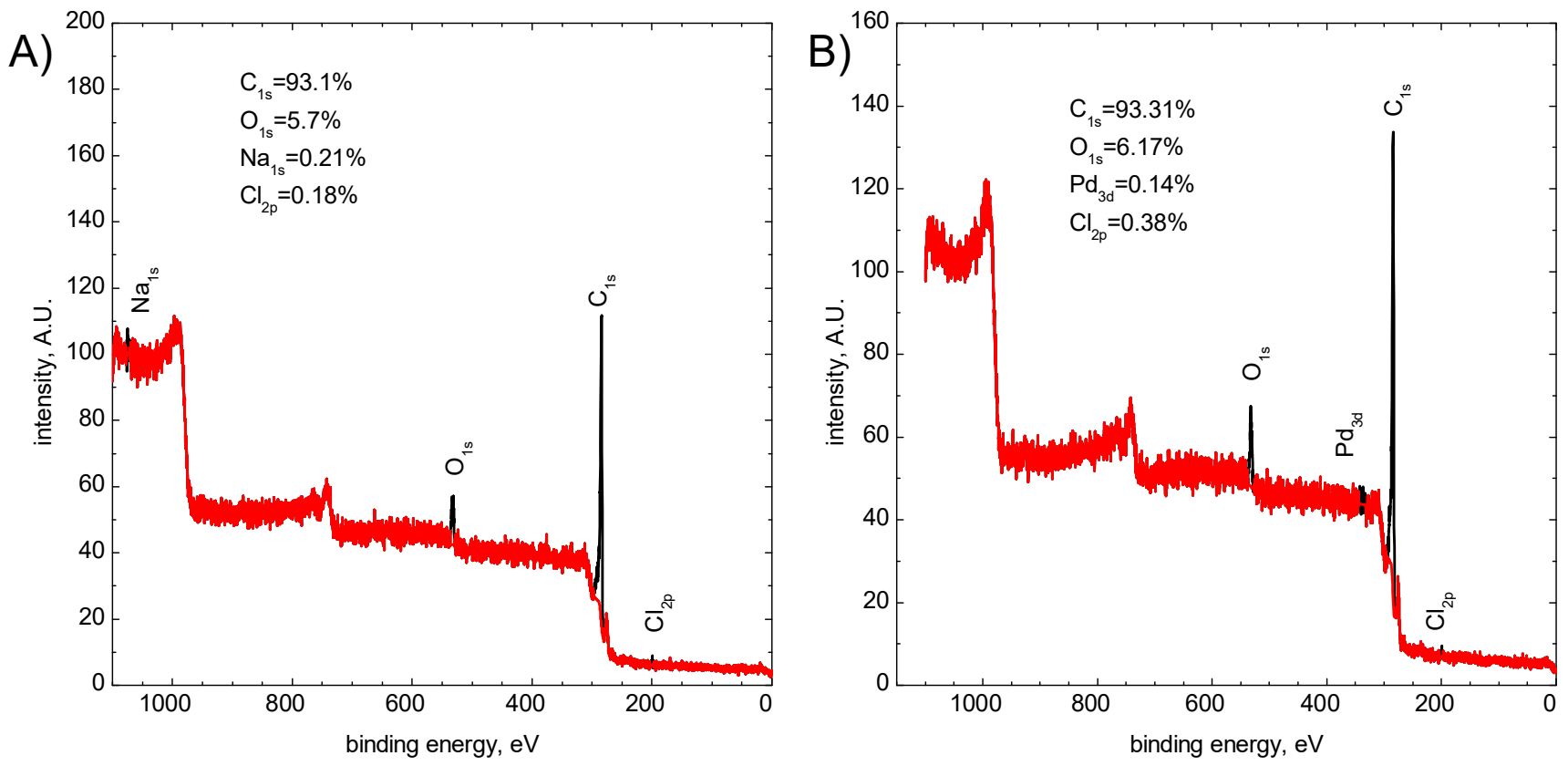

Fig. 1. XPS survey spectrum of activated carbon A) before adsorption B) after adsorption of Pd(II) chloride complex ion

particles have mash $8 \times 30$, and the typical surface area declared by producer is equal to $928 \mathrm{~m}^{2} / \mathrm{g}$ [17]. Detailed information about porosity, zeta potential etc. can be found in the previous paper [18].

XPS analysis were performed using powdered samples using SES R4000 (Gammadata Scienta, Sweden). This system is equipped with a hemispherical analyzer, and works under ultrahigh vacuum (UHV) $\left(3 \times 10^{-10} \mathrm{mbar}\right)$. The $\mathrm{Mg} \mathrm{K} \alpha$ source of incident energy of $1256.6 \mathrm{eV}$ was applied to generate core excitation. The spectrometer was calibrated according to ISO 15472:2001.

\section{Results}

\subsection{XPS spectrum analysis of AC after and before adsorption process}

In the first step, final product of the adsorption process was analyzed. The knowledge of the form of the final product, enables the reaction mechanism to be postulated. Survey spectrum of activated carbon before and after adsorption is shown in Fig. 1.

Before adsorption, sodium and chloride atoms were detected. In this case, atomic ratio is c.a. equal to 1:1. This suggests that the presence of sodium and chloride atoms is related to sodium chloride present in AC. After adsorption, sodium atoms are not observed. This suggests that sodium chloride was dissolved and removed from AC. Moreover, it can be seen, that there is two times more chlorine then palladium atoms (see Fig. 1) it suggests that formed on the surface species have stoichiometry 2 to 1 respectively.

However, to make sure, additional experiments are required. Detailed analysis of palladium binding energy spectrum gives the information about electronic state of this element. This result is shown in Fig. 2.

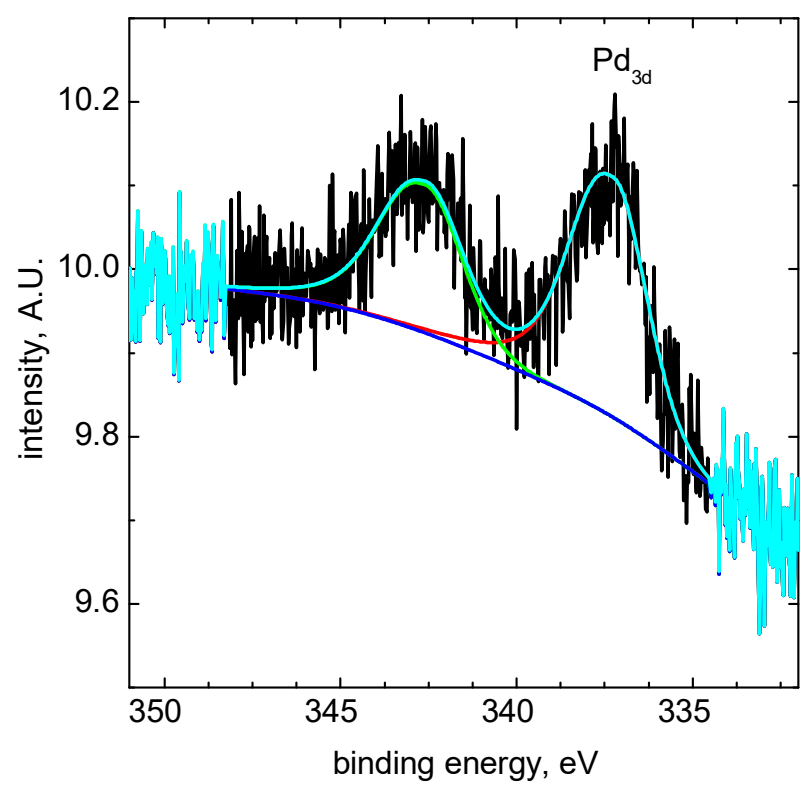

Fig. 2. High resolution of XP spectra of the Pd3d core excitation

From high resolution XP spectra of Pd3d core excitations it can be concluded that palladium exists on the surface in the form of $\mathrm{Pd}(\mathrm{II})$, and is probably bonded to organic compounds. In this case, it is suggested that $\mathrm{Pd}(\mathrm{II})$ is adsorbed directly on the functional groups. This suggestion is supported by the high resolution XPS analysis of O1s line (see Fig. 3A,B).

It can be seen, that the fraction of each specific type of functional groups is different before and after experiments. Unfortunately, it is impossible to identify which type of group is responsible for $\mathrm{Pd}(\mathrm{II})$ binding. 

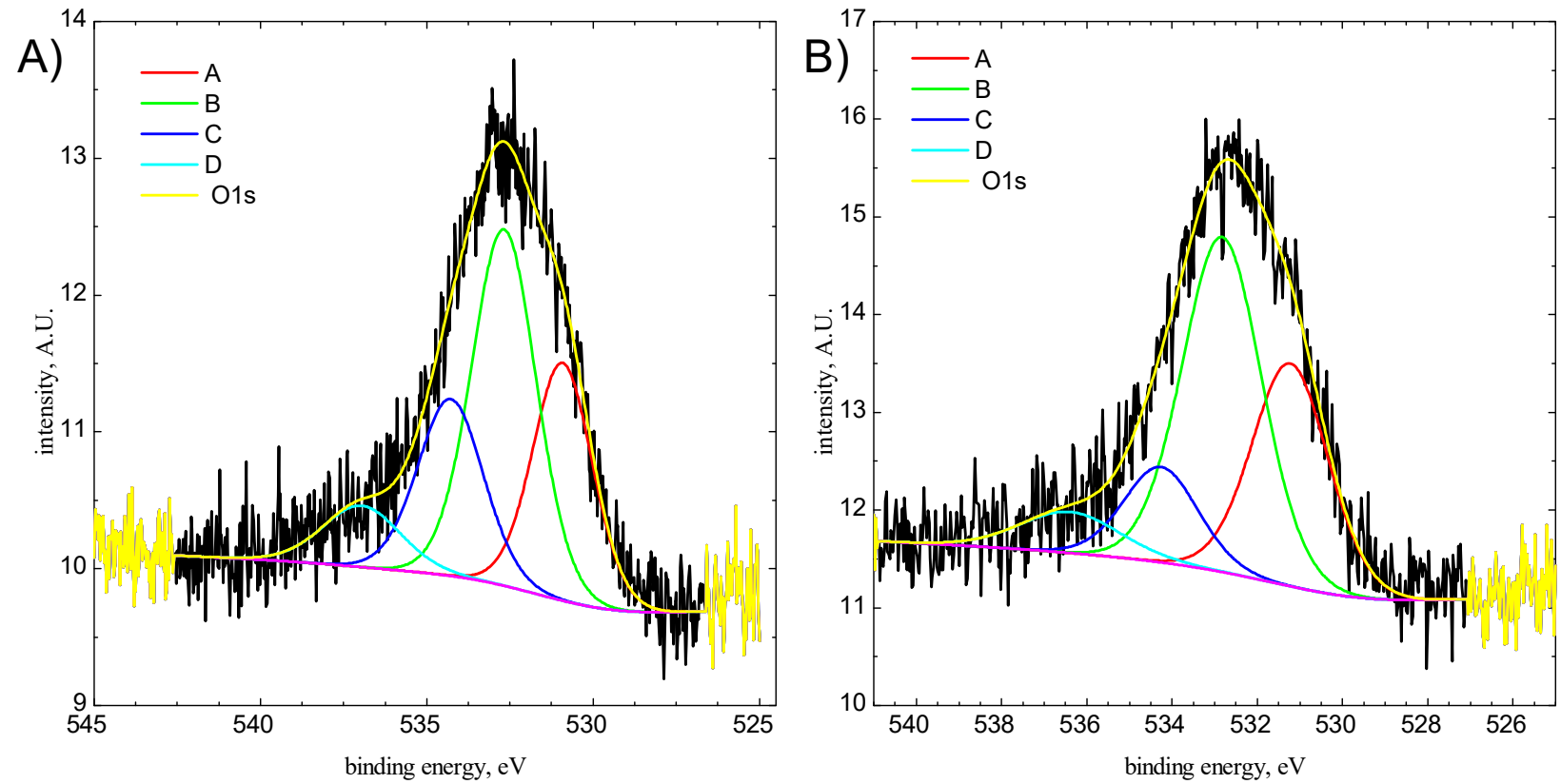

Fig. 3. High resolution of XPS spectra of the O1s core excitation A) before adsorption, and B) after adsorption

\subsection{Kinetic curve analysis}

An example of a kinetic curve obtained during experiment is shown in Fig. 4. Kinetic curve in the following form was fitted to experimentally obtained points:

$$
[P d(I I)]_{t}=W_{1} \cdot e^{-\gamma_{1} \cdot t}-W_{2} \cdot e^{-\gamma_{2} \cdot t}
$$

where

$$
[P d(I I)]_{t}-\text { concentration of } \mathrm{Pd}(\mathrm{II}) \text { complex in ti- }
$$
me " $t$ ",

$W_{1}, W_{2}$, and $\gamma_{1}, \gamma_{2}-$ are fitted parameters.

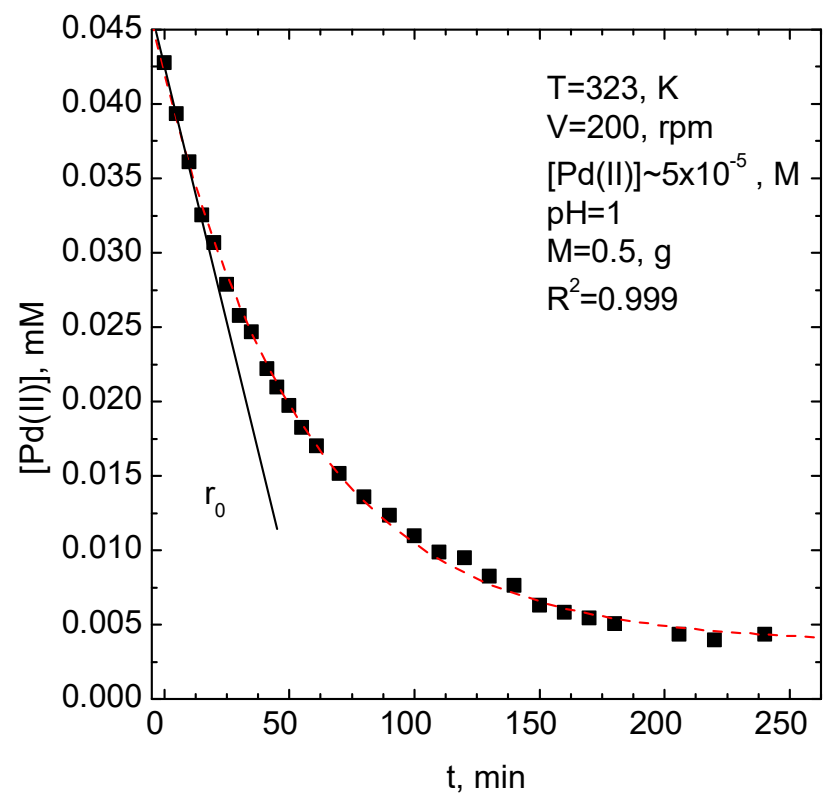

Fig. 4. An example of kinetic curve obtained during kinetic studies
Between these parameters following relationship exist:

$$
\begin{aligned}
& W_{1}=\frac{\left[P d C l_{4}^{2-}\right]_{0}}{\gamma_{2}-\gamma_{1}} \cdot\left(k_{2, o b s}+k_{3, o b s}-\gamma_{1}\right) \\
& W_{2}=\frac{\left[P d C l_{4}^{2-}\right]_{0}}{\gamma_{2}-\gamma_{1}} \cdot\left(k_{2, o b s}+k_{3, o b s}-\gamma_{2}\right)
\end{aligned}
$$

and

$$
\begin{gathered}
\gamma_{1} \cdot \gamma_{2}=k_{1, o b s} \cdot k_{3, o b s} \\
\gamma_{1}+\gamma_{2}=k_{1, o b s}+k_{2, o b s}+k_{3, o b s}
\end{gathered}
$$

This kinetic equation was adopted from [21].

This model was previously applied to describe the process of Pd(II) adsorption on NORIT ROX 0.8 [14] as well as Pt(IV) on Organosorb 10 CO $8 \times 30$ carbons [17].

Suggested, kinetic equation corresponds to the following two-step reaction scheme (see eq. (7)):

$$
\mathrm{PdCl}_{4}^{2-}+A C \underset{k_{2}}{\stackrel{k_{1}}{\rightleftarrows}} P d C l_{4}^{2-}\left|A C \stackrel{k_{3}}{\longrightarrow} P d C l_{2}\right| A C+2 C l^{-}
$$

which can be simplified assuming that the amount of applied activated carbon is in excess. Then, following relations can be introducend:

$$
\begin{aligned}
& k_{1, o b s}=k_{1} \cdot[A C] \\
& k_{2, o b s}=k_{2} \cdot[A C] \\
& k_{3, o b s}=k_{3} \cdot[A C]
\end{aligned}
$$

Consequently, the proposed model can be simplified to the following form:

$$
P d C l_{4}^{2-} \underset{k_{2}, o b s}{\stackrel{k_{1}, o b s}{\longrightarrow}} P d C l_{4, a d s}^{2-} \stackrel{k_{3}}{\longrightarrow} P d C l_{2}+2 C l^{-}
$$


The change of concentration of $\mathrm{Pd}(\mathrm{II})$ can be expressed in the form of differential equations system which solution has a form of eq. (2).

\subsection{The influence of $P d(I I)$ initial concentration on the process kinetics}

Initial rate method was applied to observe the influence of $\operatorname{Pd}(\mathrm{II})$ initial concentration on the process kinetics. The, initial rate $r_{0}$ was determined as shown in Fig. 4 from the concentration vs. time dependence.

Initial rate can be expressed in the following form:

$$
\frac{d[P d(I I)]}{d t}=r_{0}=-k_{1, o b s} \cdot[\operatorname{Pd}(I I)]^{\alpha}
$$

$r_{0}$ can be determined graphically as a slope of line fitted to kinetic curve for $\Delta t \approx 0$. The order of the reaction can be determined using logarithmic form of eq. (12) :

$$
\log \left(r_{0}\right)=\alpha \cdot \log (P d(I I))+\log \left(k_{1, o b s}\right)
$$

Obtained results are shown in Fig. 5.

The order of the reaction was determined and is equal to $1.07 \pm 0.19$. This value is in good agreement with assumed reaction scheme. Moreover, it is possible to double check assumed kinetic model using obtained data. From eq. (13) it can be seen that using intercept $k_{1, o b s}$ can be calculated. From initial rate method $k_{1}$ was calculated and is equal to $0.081 \pm 0.018 \mathrm{~min}^{-1}$, where $k_{1, o b s}$ determined from kinetic model is equal to $0.043 \mathrm{~min}^{-1}$. Taking in to account eq. (8) from $\mathrm{k}_{1, o b s} k_{1}$ can be calculated and under this conditions is equal to $0.086 \mathrm{~min}^{-1}$.

As it can be seen, values are in the same order, and can be

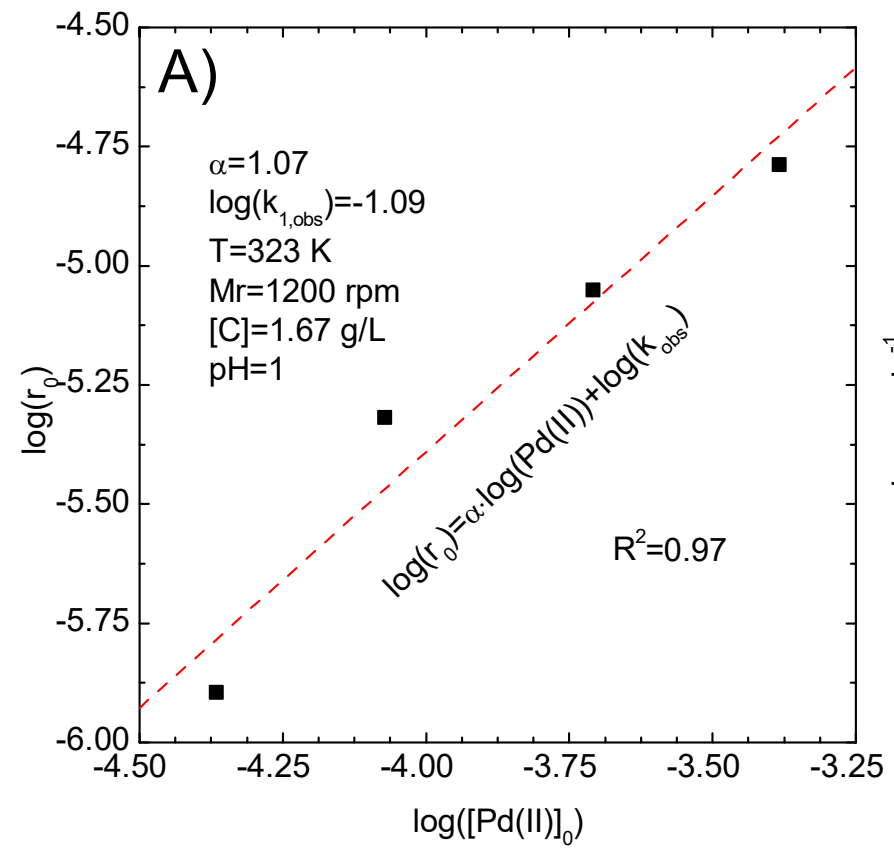

assumed as equal, since error obtained from initial rate method is significant.

It is also important to note, that determined $k_{x, o b s}$ are independent of initial concentration of Pd(II).

\subsection{The influence of AC initial concentration on observed process rate}

The influence of $A C$ initial concentration on observed process rate was also investigated. For this purpose, different amounts of $A C$ was added to solution containing $\mathrm{Pd}(\mathrm{II})$ ions. All other parameter were kept constant. Obtained results are shown in Fig. 6.

According to assumed kinetic model, $k_{x, o b s}$ are a function of AC initial concentration and should pass through the origin of the system. In case of $k_{1, o b s}$ and $k_{2, o b s}$, such a correlation exists and can be confirmed by the value of $R^{2}$. However in case of $k_{3, o b s}$ it seems that this value is not depended on $A C$ initial concentration. Therefore, it should be rather expressed as follows:

$$
k_{3, o b s}=k_{3}
$$

\subsection{The influence of temperature on the process rate coefficients}

To determine activation energy of the process, Arrhenius dependence was applied:

$$
k_{x, o b s}=A_{x} \cdot e^{-\frac{E_{a, x}}{R T}}
$$

where: $A_{x}$ - pre-exponential factor of $x$-th reaction, $E_{a, x}-$ acti-

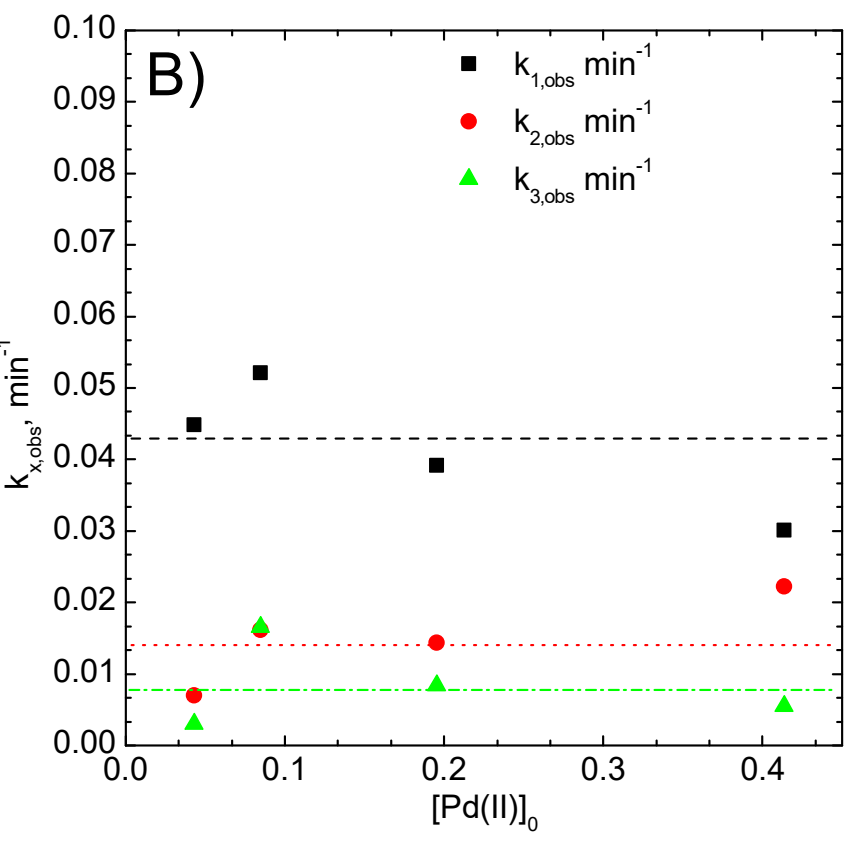

Fig. 5. A) determination of the rate order using graphical method, B) the influence of $\mathrm{Pd}(\mathrm{II})$ initial concentration on $k_{x, o b s}$ 


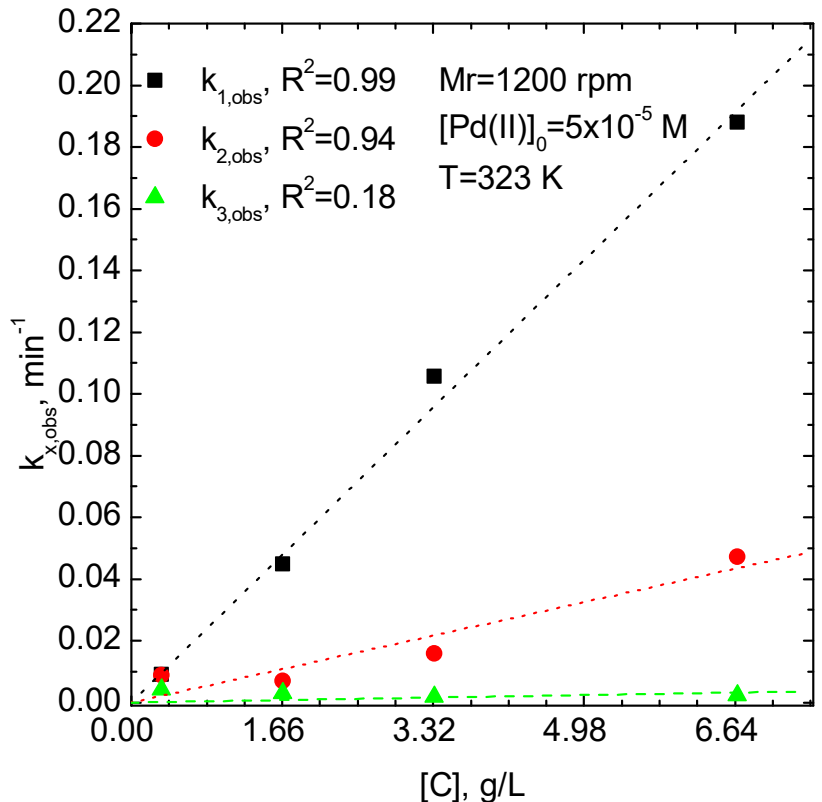

Fig. 6. Influence of AC initial concertation on the observed rate coefficient

vation energy of $x$-th reaction, $T$ - temperature, $R$ - gas constant.

To determine the $E_{a, x}$ and $A_{x}$ from the experimental data, logarithmic form of eq. (15) can be applied:

$$
\ln \left(k_{x, o b s}\right)=\ln \left(A_{x}\right)-\frac{E_{a, x}}{R T}
$$

Using $\ln \left(k_{x, o b s}\right)$ v.s. $1 /$ T plot, from its slope and intercept, activation energy as well as pre-exponential factors can be determined. Obtained results are shown in Fig. 7.

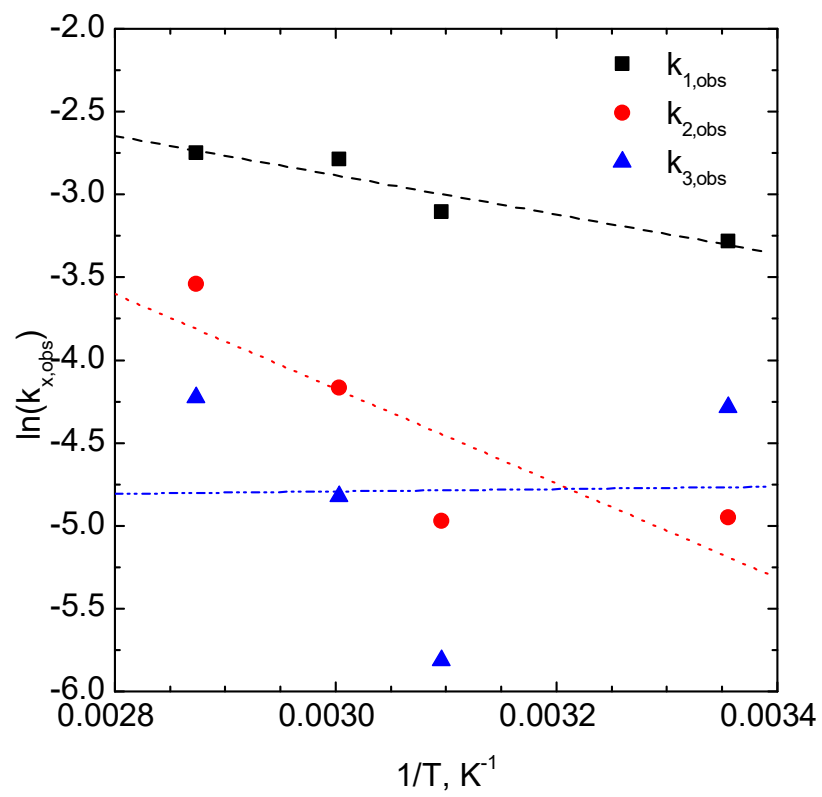

Fig. 7. Influence of temperature on $k_{x, o b s}$

Table 1 shows values of slopes and intercepts determined from the plots in Fig. 7 .
TABLE 1

Calculation of activation energy and pre-exponential factor

\begin{tabular}{|l|c|c|c|c|c|}
\hline \hline & Intercept & Slope & $\boldsymbol{R}^{\mathbf{2}}$ & $\boldsymbol{E}_{\boldsymbol{a}}, \mathbf{~ k J} / \mathbf{m o l}$ & $\boldsymbol{A}, \mathbf{~ m i n}^{\mathbf{- 1}}$ \\
\hline$k_{1, o b s}$ & $0.7 \pm 0.9$ & $-1182.4 \pm 301.6$ & 0.83 & $9.8 \pm 2.5$ & $4.6 \pm 8.5$ \\
\hline$k_{2, o b s}$ & $4.4 \pm 3.9$ & $-2857.6 \pm 1271.6$ & 0.57 & $23.8 \pm 10.6$ & $25118.9 \pm 7943.3$ \\
\hline$k_{3, o b s}$ & $-5 \pm 7.9$ & $71.14 \pm 2551.9$ & 0.01 & $-0.6 \pm 21.2$ & $0 \pm 7.9 \times 10^{7}$ \\
\hline
\end{tabular}

For the first step, activation energy is small and is equal to $9.8 \pm 2.5[\mathrm{~kJ} / \mathrm{mol}]$. In case of the second step activation energy is much higher and is equal to $23.8 \pm 10.6[\mathrm{~kJ} / \mathrm{mol}]$. However, it hast to be noted that obtained value of $R^{2}$ is low. Determined standard deviation of activated energy is also high. This might to be related to error propagation during calculations. In case of $k_{3, \text { obs }}$ obtained $R^{2}$ is low, and it seems that there is no energetic barrier or is very low.

\subsection{Adsorption isotherm}

One of the most important relations describing adsorption process is adsorption isotherm. During the last century significant amount of different isotherms was developed to describe this process. Among them, probably one of the most often applied is Freundlich isotherm [22]. This isotherm has no theoretical background, and was developed to describe adsorption from aqueous systems, like is adsorption of metal ions from water base solutions. The Freundlich isotherm [22] originally was given in the following form:

$$
\frac{x}{m}=\beta \cdot c^{\frac{1}{n}}
$$

where:

$x$ - amount of adsorbed substance,

$m$ - mass of applied sorbent, $\mathrm{g}$,

$\beta$ - constant, dependent on temperature and studied system,

$c$ - equilibrium concentration of adsorbed substance,

$1 / n-$ constant, dependent on temperature and studied system.

It can be seen, that it is a nonlinear equation. Therefore, it was proposed by Freundlich to used its logarithmic form which can be given as follows:

$$
\log \left(\frac{x}{m}\right)=\frac{1}{n} \cdot \log (c)+\log (\beta)
$$

Having plot $\log \left(\frac{x}{m}\right)$ v.s. $\log (\mathrm{c})$ fit it is possible to determine $1 / n$ and $\log (\beta)$ parameters from the slope and intercept, respectively.

In Fig. 8 kinetic curve obtained during adsorption isotherm investigation are shown. As it can be seen, time required to obtain equilibrium state strongly depends on initial concentration of $\mathrm{Pd}(\mathrm{II})$ chloride complex ions. Moreover, the equilibrium concentration also strongly depends on initial concentration of $\operatorname{Pd}(\mathrm{II})$ chloride complex ions. As an equilibrium state it was 

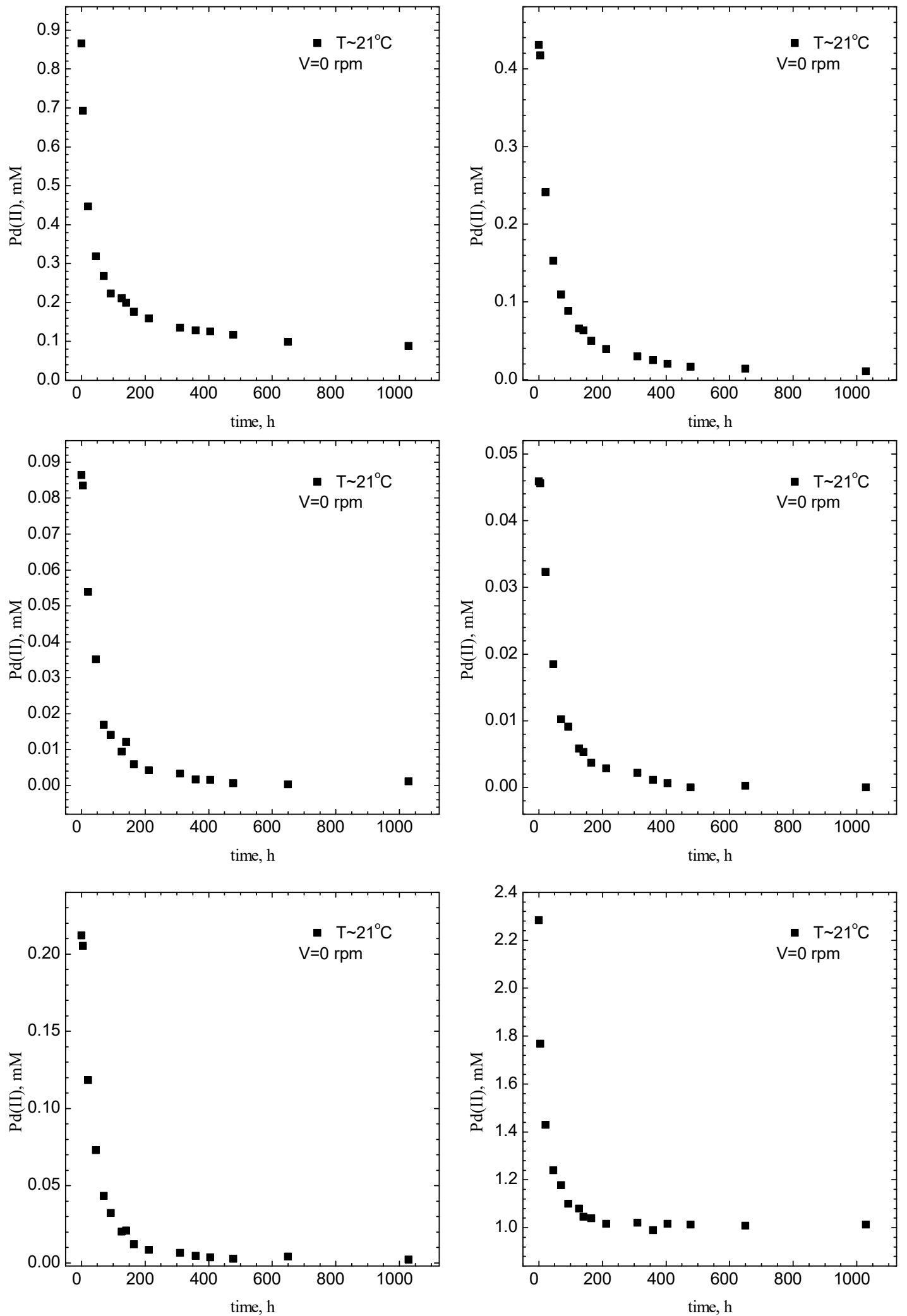

Fig. 8. Experimental kinetic curves obtained during determination of $\mathrm{Pd}(\mathrm{II})$ adsorption isotherm

assumed situation, when during time an random fluctuation of concentration of $\mathrm{Pd}(\mathrm{II})$ chloride ions in the solution is observed. This was assumed as confirmation, that the changes of concentration is smaller than applied method precision. Next, the amount of adsorbed $\mathrm{Pd}(\mathrm{II})$ was calculated as difference between initial concentration and equilibrium one.
In Fig. 9 Freundlich adsorption isotherm is shown. The $R^{2}$ parameter is very high end is equal to 0.986 . This in turn suggests that applied model well described obtained results.

The $1 / n$ parameter is equal to $0.32 \pm 0.03$ and the $\beta$ is equal to 0.028 . 


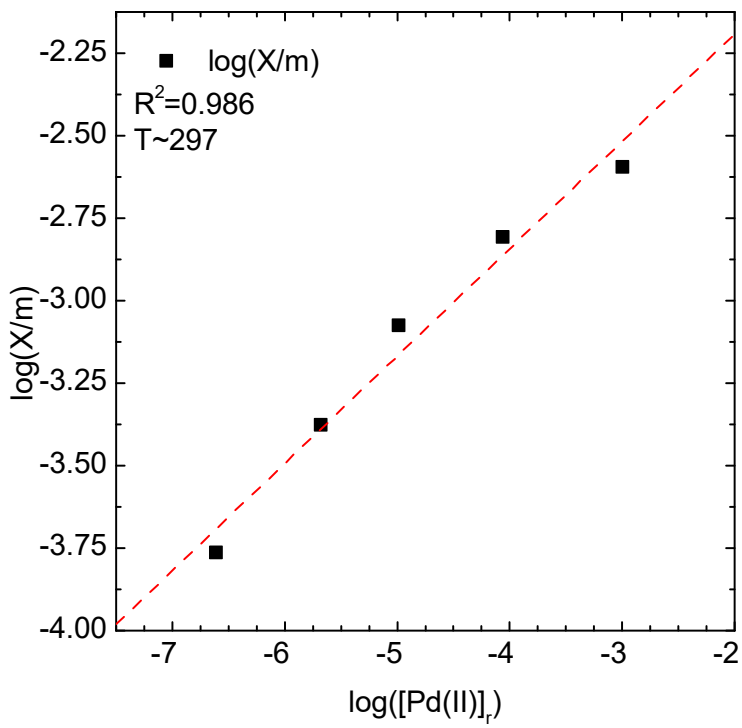

Fig. 9. Freundlich adsorption isotherm

\section{Conclusions}

Kinetic studies of the adsorption of Pd(II) chloride complex ions on activated carbon have been described. Obtained results confirmed that applied kinetic model describes the process well.

Application of the initial rate methods allowed to determine the order of the reaction in respect to Pd(II) initial concentration. Moreover, studies of the influence of the amount of AC on the process kinetics also confirmed that the proposed model is consistent.

However, still there is a lack of connection between kinetic results and adsorption isotherm. There is no doubt, that such a correlation has to exist. Therfore, it's systematic studies are needed to get required amount of results to validate the model.

Application of Arrhenius equation to determine the activation energy of each steps gives doubtful results. It is mainly due to high standard deviation and probably by error propagation during individual calculations.

\section{Acknowledgments}

I would like to thanks prof Krzysztof Fitzner for his constant encouragement and help in my work.

I would like to thanks to dr Robert P. Socha, for his help during XPS measurement and data analysis. Activated carbon was kind supplied by Desotec Polska.

This work was supported by the National Science Center of Poland under grand number 2016/23/D/ST8/00668 Sontata 12

\section{REFERENCES}

[1] B. Singh, N. Bhardwaj, V.K. Jain, V. Bhatia, Sensors and Actuators A: Physical 220, (2014).

[2] M. Gómez-Martínez, E. Buxaderas, I.M. Pastor, D.A. Alonso, Journal of Molecular Catalysis A: Chemical, 404-405 (2015).

[3] M.A. Barakat, M.H.H. Mahmoud, Y.S. Mahrous, Applied Catalysis A 301, 182 (2006).

[4] M.K. Jha, J.C. Lee, M.S. Kim, J. Jeong, B.S. Kim, V. Kumar, Hydrometallurgy 133, (2013).

[5] M.H. Morcali, B. Zeytuncu, O. Yucel, Mater. Res. 16, (2013).

[6] S.A. Simanova, A.V. Shukarev, A.A. Lysenko, S.F. Grebennikov, O.V. Astashkina, Fibre Chemistry 40, 365 (2008).

[7] A. Wołowicz, Z. Hubicki, Industrial and Engineering Chemistry Research 51, (2012).

[8] A. Wołowicz, Z. Hubicki, Industrial and Engineering Chemistry Research 51, (2012).

[9] A. Wołowicz, Z. Hubicki, Chemical Engineering Journal 174, (2011).

[10] K. Mech, P. Żabiński, R. Kowalik, K. Fitzner, Journal of The Electrochemical Society 160, (2013).

[11] K. Mech, P. Żabiński, R. Kowalik, T. Tokarski, K. Fitzner, Journal of Applied Electrochemistry 44, (2014).

[12] M. Wojnicki, K. Fitzner, M. Luty-BŁocho, Trans Nonferrous Met. Soc. China 25, (2015).

[13] M. Wojnicki, K. Pacławski, R.P. Socha, K. Fitzner, Trans. Nonferrous Met. Soc. China 23, 1147 (2013).

[14] M. Wojnicki, R.P. Socha, M. Luty-Błocho, K. Fitzner, Reaction Kinetics, Mechanisms and Catalysis 120, (2017).

[15] M. Wojnicki, M. Luty-Błocho, R. Socha, K. Mech, Z. Pędzich, K. Fitzner, E. Rudnik, Journal of Industrial and Engineering Chemistry 29, 289 (2015).

[16] M. Wojnicki, E. Rudnik, M. Luty-Błocho, K. Pacławski, K. Fitzner, Hydrometallurgy 127-128, 45 (2012).

[17] M. Wojnicki, E. Rudnik, R.P. Socha, K. Fitzner, Australian Journal of Chemistry 70, (2017).

[18] M. Wojnicki, E. Rudnik, M. Luty-Błocho, R.P. Socha, Z. Pędzich, K. Fitzner, K. Mech, Australian Journal of Chemistry 69, 254 (2016).

[19] M. Wojnicki, Reaction Kinetics, Mechanisms and Catalysis, (2017).

[20] A. Podborska, M. Wojnicki, Journal of Molecular Structure 1128, (2017).

[21] V. Korobov, V. Ochkov, Chemical Kinetics with Mathcad and Maple, 2011.

[22] H. Freundlich, Z. Phys. Chem. 57, 385 (1906). 